University of Tennessee Health Science Center UTHSC Digital Commons

Fall 12-2018

\title{
Telehealth in Rural Tennessee- Closing the Gap in Care?
}

Kara L. Bianchini

University of Tennessee Health Science Center

Follow this and additional works at: https://dc.uthsc.edu/hiimappliedresearch

Part of the Health and Medical Administration Commons, and the Health Information Technology Commons

\section{Recommended Citation}

Bianchini, Kara L., "Telehealth in Rural Tennessee- Closing the Gap in Care?" (2018). Applied Research Projects. 64. . https://doi.org/10.21007/chp.hiim.0059

https://dc.uthsc.edu/hiimappliedresearch/64

This Research Project is brought to you for free and open access by the Department of Health Informatics and Information Management at UTHSC Digital Commons. It has been accepted for inclusion in Applied Research Projects by an authorized administrator of UTHSC Digital Commons. For more information, please contact jwelch30@uthsc.edu. 


\author{
Kara Bianchini \\ Telehealth in Rural Tennessee- Closing the Gap in Care? \\ Master of Health Informatics and Information Management \\ University of Tennessee Health Science Center \\ Advisor: Dr. Sajeesh Kumar
}

Fall 2018 


\begin{abstract}
Telehealth is quickly becoming a tool used in everyday healthcare. Certain areas, such as rural communities in Tennessee, experience health disparities because of their location and distance from health care providers. This gap in care can be diminished through the use of telehealth services. This research project is taking place to gather data from hospitals in Tennessee currently providing telehealth services. I want to determine if telehealth is closing the gap-in-care seen in rural communities. Through research, I have found there are multiple barriers to telehealth, but also significant benefits. I think with additional education and training, telehealth can become a strong resource for individuals in all communities.
\end{abstract}




\section{Table of Contents}

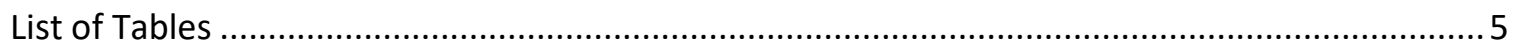

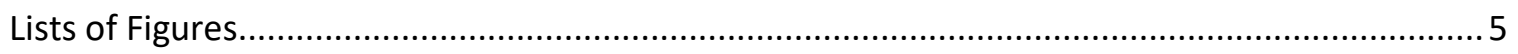

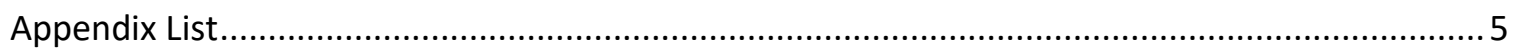

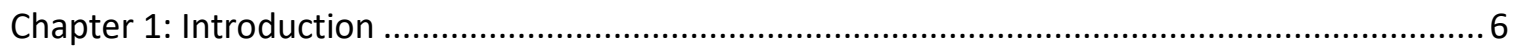

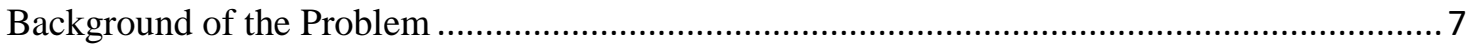

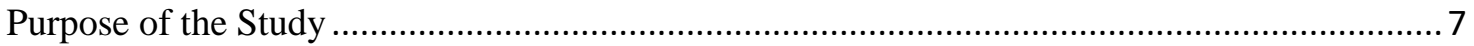

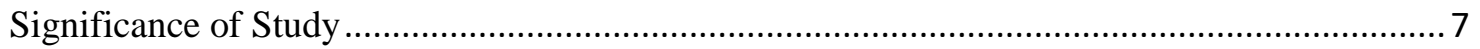

Conceptual frame of reference (Theoretical Framework).................................................... 8

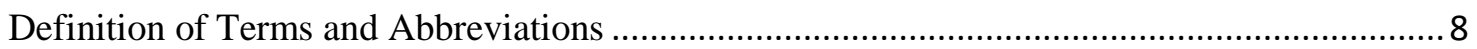

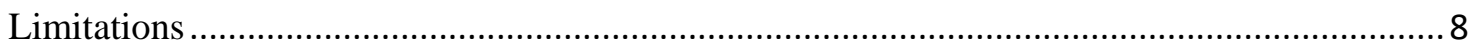

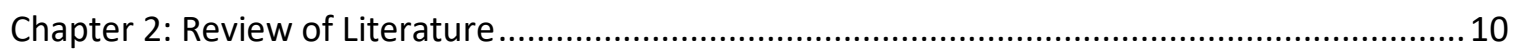

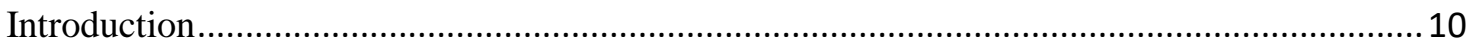

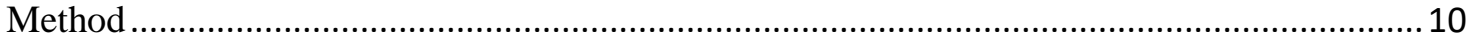

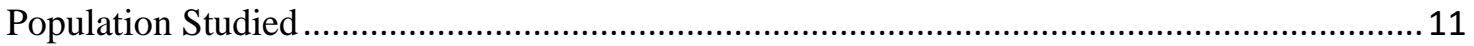

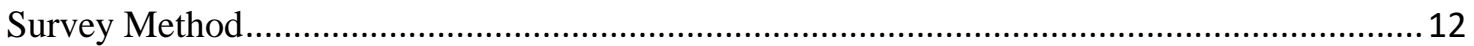

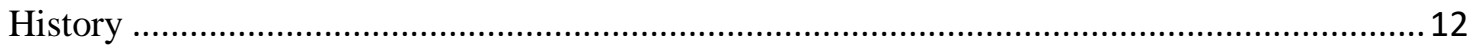

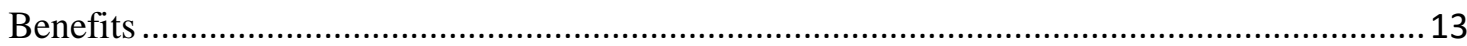

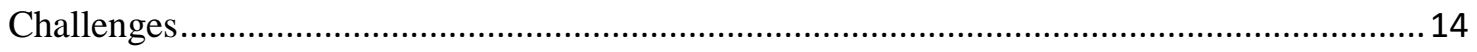

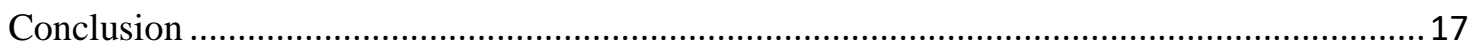

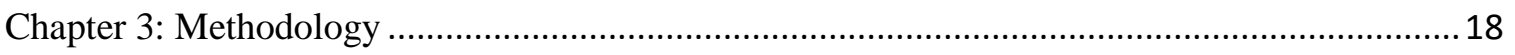

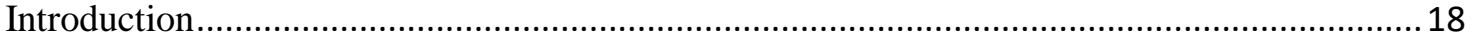

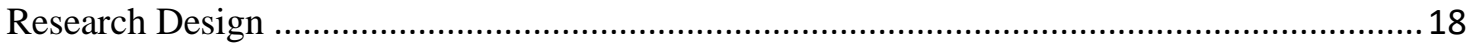

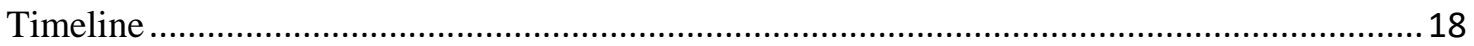

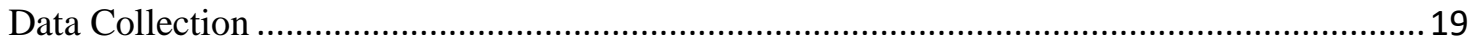

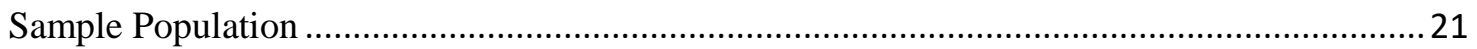

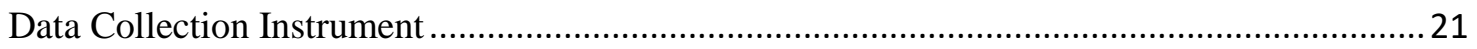

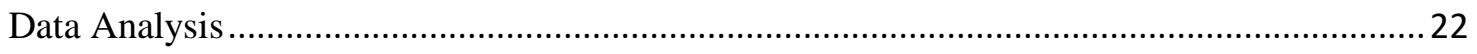

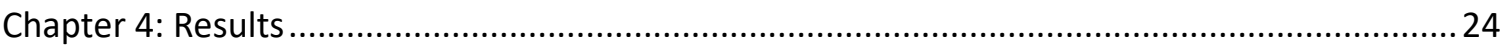

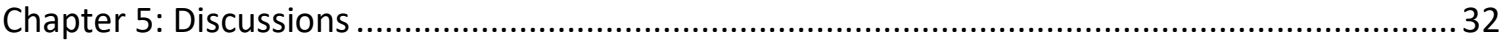

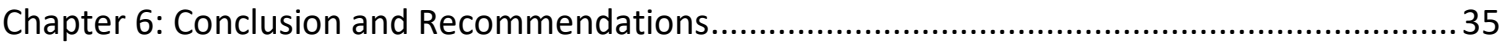

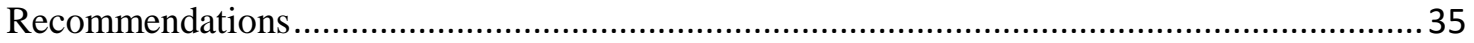




\section{TELEHEALTH IN RURAL TENNESSEE}

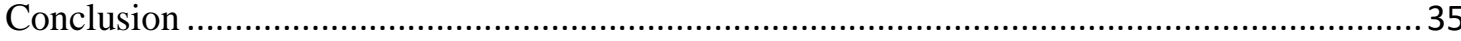

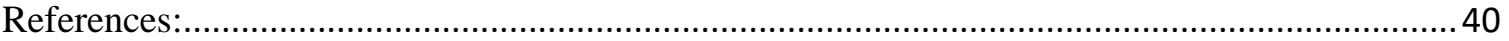


List of Tables

Table-1 Project Timeline

Table-2 Cost Efficiency by Position

Table-3 Cost Efficiency by Position Excel Formulas

Table-4 Care Improvement by Position

Table-5 Care Improvement by Position Excel Formulas

Lists of Figures

Figure-1 Respondents' Position in Organization

Figure-2 Age of Respondent

Figure-3 Place of Employment

Figure-4 Years Utilizing Telehealth

Figure-5 Cost Efficiency of Telehealth

Figure-6 Patient Care Improvement

Figure-7 Telehealth Connectivity Issues

Figure-8 Telehealth's Greatest Barriers

Figure-9 Patient Retention

Figure-10 Responses to Open Ended Question

Appendix List

Appendix-A Recruitment letter

Appendix- B Questionnaire 


\section{Chapter 1: Introduction}

Tennessee is well known for being the home of country music as Nashville, "The Music City", is nestled in the heart of middle Tennessee. While urban areas of the state are expanding at an unprecedented rate, there are less populated, rural counties in Tennessee without such growth. Rural areas have an abundance of undeveloped land, farmland or forest. Based on the 2010 census, $93 \%$ of Tennessee is considered rural (TN Department of Health, n.d.). Urban and rural areas have different levels of access to healthcare, nutritious food, and telecommunications. Unfortunately, the different levels experienced by rural areas have created harsh health care disparities within communities. The State of Tennessee is working diligently to address the health concerns in rural areas by providing funding for health programs and implementing health IT into healthcare organizations. One form of health IT that has the capability of lessening the disparities is a comprehensive telehealth technology that meets the evolving needs of health care.

Telehealth has created an abundance of opportunities to spread cost-effective, quality care to rural communities. Telehealth can improve access to care in rural areas by introducing real-time interactive communication between patients and providers without the need to travel to a distant location. By focusing on healthcare through telecommunication devices, such as telehealth, organizations can present the opportunity of improved access to care at a lower cost. 


\section{Background of the Problem}

As the cost of healthcare is on the rise, both providers and consumers are experiencing the financial burden. Hospitals in rural Tennessee are closing from a lack of funding, and as a result, creating greater disparities and expanding the gap of care. McNairy Regional Hospital is one example of a rural hospital that has recently closed. This former hospital located in Selmer, TN was a source of care for residents of the rural town. Since the hospital closed in May 2016, residents now need to travel to the next county which is about a 20-mile drive to receive care and even further distances for specialty care. The community has expressed concern that care is not easily accessibleespecially in the event of an emergency (Jackson, 2018). Introducing telehealth to this community can help lessen the burden of having their hospital shut down.

\section{Purpose of the Study}

The purpose of this study is to gather data on telehealth from a healthcare provider's perspective. Many surveys state the positive impact that telehealth has on a population, but it is unclear the operational state, or financial status, of the facilities performing the telehealth services. As such, this study will look inside the facility to see if how their telehealth services operate, the patient impact, benefits and challenges, and the cost effectiveness of telehealth services.

\section{Significance of Study}


To date, there is a lack of research on the topic of telehealth specific to rural Tennessee. By researching telehealth services and bring light to barriers that are restricting access to these services, there is hope that communities in rural Tennessee will gain access to healthcare's innovative technology.

\section{Conceptual frame of reference (Theoretical Framework)}

This project is based on the opinions of healthcare professionals, both administrative and clinical, regarding telehealth in rural Tennessee.

\section{Definition of Terms and Abbreviations}

Health disparity- Is a preventable difference in the burden of disease, injury, violence or opportunities to achieve optimal health that are experienced by socially disadvantaged populations (TN Department of Health, n.d.).

Telehealth- Remote healthcare services using telecommunications technology.

Health IT- Health IT is a term used that refers to the electronic systems healthcare professionals and patients use to store, share, and anaylze health information (ONC, n.d)

CHS- Community Health Systems

IRB- Institutional Review Board

\section{Limitations}

There are multiple limitations to this study. Surveys were disseminated to facilities in only one health care system, CHS. Other organizations may offer different 
services or use a different telehealth platform and in result yield different outcomes and responses. The amount of funding per hospital is also a limitation for this project. There are healthcare organizations that have the financial capabilities to offer more resources than the facilities that were surveyed for this project--producing different outcomes. Also, there is the possibility for biased answers. Individuals who favor telehealth services may be more inclined to take time to share their experiences. 


\section{Chapter 2: Review of Literature}

\section{Introduction}

The purpose of this section is to analyze previous research and studies on telehealth in rural Tennessee. While searching past literature, minimal results showed recent research in Tennessee. As such, the articles selected either did not disclose a location or was based in states other than Tennessee.

Telehealth is a resource that is taking over the healthcare industry to provide better access to quality care at a lower cost. To better understand the perception, benefits, and barriers of telehealth, researchers around the world have been conducting studies and researching this topic for years. While undertaking this research project, I reviewed published literature to gather information on the history, barriers, and benefits observed through multiple surveyors.

\section{Method}

I used two search engines to locate studies on Telehealth in rural Tennessee. The first search was in the American Health Information Management Association (AHIMA) Body of Knowledge (BoK) database using the phrase "telehealth rural Tennessee." This query yielded 25 results, none of which applied to this research project. There were studies on specialized telehealth, such as Nero-telehealth, but for this project, a more generalized paper is preferred. 
The three articles selected for the literature review were obtained through a Google search with keywords "telehealth rural Tennessee." Focusing on the most relevant results, I selected three papers. The first was published in March 2017 by The Rural Broadband Association (NTCA), titled Anticipating Economic Returns of Rural Telehealth. This White Paper breaks down the challenges and the non-quantifiable and quantifiable benefits of telehealth in rural communities. The second article, titled The Role of Telehealth in an Evolving Health Care Environment: Workshop Summary (2012), provides excerpts from medical providers and healthcare professional on hot topics of telehealth. This paper was selected for the literature review because it provides an amalgam of opinions of the potential and challenges of telehealth in rural communities. Lastly, a survey conducted by Foley \& Lardner LLP Law group was selected as it is a good fit for this literature review because of their extensive questions on telehealth in the community. Foley has a Telemedicine Industry Team that helps clients embrace the emerging issues of telehealth, enabling them "...to provide innovative care for patients in new markets around the block and around the world." (Foley \& Lardner, pg. 17, 2017).

\section{Population Studied}

Each of the three pieces of literature has a focus of telehealth in communities, but all from different organizational perspectives. The telehealth and digital health survey by Foley and Lardner LLP focused on senior-level executives and health care providers in hospitals, specialty clinics, ancillary services and related organizations, in Florida, Massachusetts, California, and New York. This study did not specify if the areas of the healthcare facilities were considered rural or urban/metropolitan. 
Similarly, the study by Schadelbauer titled Anticipating Economic Returns of Rural Health focused on multiple states-Arkansas, Kansas, Oklahoma, and Texas. Each of these states has rural environments that benefit from telehealth. This survey took both the hospital and the patient/caregiver into consideration when estimating the economic benefits of telehealth.

Lastly, the workshop summary provides thoughts of health care professionals from hospitals, universities, American Telemedicine Association, and the Health Resources and Services Administration. By having an amalgam of professional backgrounds, this workshop summary provides views of telehealth from multiple populations.

\section{Survey Method}

Of the three sources for the literature review, only one sent out surveys to participants. Foley distributed their study in the third quarter of 2017 and received responses from 107 senior-level executives and healthcare providers in hospitals, specialty, clinics, ancillary services, and other healthcare related organizations. Foley's survey had a total of 26 questions and focused on telehealth in both regional and international locations.

\section{History}

Dr. Thomas Nesbitt describes the history of telehealth in an excerpt of the workshop summary, titled "The Evolution of Telehealth: Where Have We Been and Where Are We Going?" In today's health care environment, telehealth is thought of as 
flat-screen, high-definition units with peripheral devices that can aid in physical examination of the patient (National Academies Press, 2012). This is true based on our current technology, but telehealth has been around for a lot longer than most think. Since the 1920's, before the lavish technology, radios were used to give medical advice to clinics on ships. Alaska is a prime example of the telehealth history in rural communities. Community health aides in small villages can perform otoscopy and audiometry, and the information can be sent to a specialist in Anchorage or Fairbanks where they would determine if the patient needed to travel to see a specialist for treatment (National Academies Press, 2012). Telehealth has come a long way since the use of radios, but it is this early technology that created a strong foundation for the telehealth services utilized today.

\section{Benefits}

There are numerous benefits of telehealth in rural communities. Schadelbauer details both quantifiable and non-quantifiable benefits in Anticipating Economic Returns of Rural Telehealth:

Non-quantifiable benefits of telehealth:

Access to specialists- Accessing specialty care can be a challenge in rural communities as physician shortages is a common challenge. Telehealth provides access to specialists well beyond patients' geographical location reducing the need to travel great distances for care. As such, telehealth gives patients a choice to select the provider they want to see, without the limitations of distance. 
Timeliness- Telehealth allows for patients to be diagnosed and treated promptly. This benefit is significant when dealing with conditions such as a heart attack, stroke, or severe trauma. A trip hundreds of miles away to the nearest medical facility could cause irreversible disability or even death.

Among the quantifiable benefits are:

Transportation costs- These costs include all travel costs incurred by a patient and caregiver when traveling to a distant healthcare facility. These costs include but are not limited to gas, tolls, and parking.

Hospital costs- The economic status of rural facilities may not make it feasible to have specialists onsite - especially if the number of special cases is low. In these situations, it would behoove facilities to implement in telehealth and "share" specialty physicians with other hospitals.

These benefits show the positive impact telehealth has on patients, caregivers, and physicians.

\section{Challenges}

Telehealth can be the answer to health disparities in rural Tennessee; however, some challenges impede the expansion of telehealth. In the workshop summary (2012) Jonathan Linkus gave a brief overview of common telehealth challenges. He referred to these challenges as the "seven deadly barriers" for telehealth. These barriers include money, regulations, hype, adoption, technology, evidence and success (National Academies Press, 2012): 
Money- Reimbursement is a significant barrier for telehealth adoption. Medicare does not reimburse very much for the fee-for-service system, and the reimbursement that does occur has many restrictions. For example, a treatment location must be a nonmetropolitan area, in a particular institute using specific procedural codes. Fear of limited reimbursement may soon diminish as CMS proposes more Medicare reimbursement for telehealth. Under CMS' proposed 2019 Medicare Physician Fee Schedule and Quality Payment Program, CMS will begin reimbursing for virtual check-in services, remote evaluation of recorded image and videos submitted by patients and expand reimbursement opportunities for "prolonged preventative services" (Wicklund, 2018).

Regulations- With the expansion of telehealth, most of the major health care providers are moving into a national system and as a result increasing the licensure barriers. When telehealth was first implemented, the systems typically operated within a single state. Today, there are multistate systems with multistate practices. There are also practice regulations where the state medical board requires an in-person consultation before permitting telehealth services (Workshop Summary, 2012).

Hype- The HealthIT community tends to focus on the positive aspects of telehealth, but there are a lot of studies that suggest that some applications of telehealth "do not work or cost too much." To expand and strengthen the use of telehealth, it is important to understand both the good and the bad.

Adoption- Because of the nationwide networks previously mentioned, there is resistance in telehealth adoption by some healthcare providers because of fear of competition against the state's telehealth network. 
Technology- Technology is becoming the focus of telehealth-implementing the newest and unique piece of equipment. Telehealth is about the service provided and the positive impact the service has on peoples' lives. It is important not to get the two factors mixed up.

Evidence- Some applications are showing significant progress through surveys; however, other areas lack large studies. For example, some large payers are ready to implement telehealth, but more evidence is required on cost-saving potential (National Academies Press, 2012).

Success- A lot of the success of telehealth services in the rural community depends on a multifaceted of factors. Is the rural network isolated from traditional telehealth networks? Are independent firms such as tele-radiology, working with the hospital or are they competing? The success of a telehealth network is not as simple as implementation and usage.

In addition to the "seven deadly barriers" are insufficiently developed technology infrastructure and lack of broadband services in rural communities. Anyone that has lived in or traveled through a rural area can attest that the lack of internet services can create feelings of frustration. This lack of adequate internet is also blocking patients from receiving the care they need. According to Schadelbauer, to have high real-time consultations, both parties need to have a high-speed, high-quality connection of at least 25 megabits per second (Mbps) downstream/3Mbps upstream. Reports from the Federal Communication Commission (FCC) show 10\% of Americans, that's 34 million people, lacked access to 25 Mbps internet. Digging even deeper, 23 million of these individuals 
lived in a rural area (Schadelbauer, 2017). Unfortunately, in Tennessee, some laws create roadblocks for the expansion of adequate internet. Under a Tennessee law enacted in 1999, any municipality operating an electric plant is authorized to offer services such as cable, internet, and video services to its residents. This service, however, is limited to communities within its service area (Leagle, 2017).

A prime example is the fiber optic network installed in Chattanooga, TN. All customers within the service area receive Gigabit services through the network. Neighboring communities, because of the geographic limitations, do not receive these fiber optic services. Surrounding areas have requested an expansion of services because the underserved areas are a "digital desert" where internet services are abysmal or nonexistent (Leagle, 2017).

\section{Conclusion}

Telehealth has, in some form or another, been around since the 1920's. Technology has expanded from radios to flat-screen televisions with peripheral devices to assist with services. There is no denying telehealth provides better access and reduces the cost of care, but barriers are also present, such as broadband, licensure and reimbursement issues. Many white paper reports and surveys demonstrate the challenges and benefits of telehealth, but few that focus on rural communities in Tennessee. Through research, I have compiled a list of benefits and challenges that I will use to compare the data collected for this research assignment. 


\section{Chapter 3: Methodology}

\section{Introduction}

The Methodology chapter will serve as an outline of the data collection process. This section will explain the tools used to collect data, the rationale behind the survey questions, and the proposed timeline for the thesis project completion.

\section{Research Design}

This research was designed based on the three White Papers in Chapter 2 Literature Review. The questions in the survey resembled those answered in previous studies. I hope to create a comparison of previously conducted telehealth research to the answers received in my study. By focusing on this comparison, I will be able to determine the level of satisfaction and utilization of telehealth in rural Tennessee compared to other urban and rural areas.

This research project was reviewed and approved by the University of Tennessee IRB. Also, from a clinical and feasibility standpoint, this project was also reviewed and approved by Compass Point Research, the compliance research group used by CHS. This group deemed the project exempt from the required Data Usage Agreement or Business Associate Agreement.

\section{Timeline}

Table-1 shown below represents the timeline visualization for project completion. 


\begin{tabular}{|l|l|l|l|l|}
\hline Timeline for Thesis Project & August & September & October & November \\
\hline Develop Topic & & & & \\
\hline Submit topic for approval & & & & \\
\hline IRB approval & & & & \\
\hline Develop questionnaire & & & & \\
\hline Disseminate questionnaire & & & & \\
\hline Begin Ch. 1-3 & & & & \\
\hline Follow-up with respondents & & & & \\
\hline Analyze data & & & & \\
\hline Write Results \& Conclusion chapters & & & & \\
\hline Submit draft paper to Advisor & & & & \\
\hline Revisions to draft & & & & \\
\hline Create powerpoint presentation & & & & \\
\hline Thesis presentation & & & & \\
\hline
\end{tabular}

(Table-1 Project Timeline)

\section{Data Collection}

This research project utilized a qualitative design. Participants received a 10question survey asking their opinion on multiple aspects of telehealth. The first four questions in the survey gathered information about the individual completing the questionnaire. This information is essential because it will show if there is any difference in opinion of telehealth based on age, position, experience or facility.

1. What is your position in the organization?

2. What is your age range?

3. What facility are you associated with?

4. How many years have you utilized telehealth? 
The position in the organization is intended to see if there is a notable difference in response between clinical and administrative staff. I added the age range to analyze the difference between younger employees and those with more experience-leading into the question of how many years of telehealth experience the respondent has. I included the facility question because some of the hospitals surveyed are more rural than others. Some may also be in better financial standing, which could affect the rate of telehealth utilization or satisfaction.

The next group of questions is intended to collect data based on the respondents' experience with telehealth.

5. In your experience, has telehealth helped improve overall patient care?

6. Do you experience connectivity issues during sessions?

7. In your opinion, what is the largest barrier for telehealth in rural Tennessee?

8. Is telehealth cost efficient?

9. What percentage of your patient population continues with telehealth services after the initial visit?

10. Please provide any additional thoughts on telehealth in your organizationbenefits, limitations

This set of questions begins by asking if telehealth improved patients' overall care. I wanted to ask this question because it gives a generalized view of the effectiveness of telehealth. The next two questions focus on barriers of telehealth. There are a lot of surveys that focus on the benefits of telehealth, but I wanted to find out the barriers faced at these facilities. By analyzing the greatest barriers to telehealth, healthcare professionals can work on the most pressing issues in hope of improving telehealth in facilities. The 
next question is about cost. Because the study population includes both administrative and clinical staff, the answers to this question could reflect a difference in opinions based on position in the organization. This question is in Foley's survey where 43\% of respondents were C-Suite Executives, which could result in contrasting responses compared to my telehealth survey. Also, the next question, the continuation of telehealth after the first visit, will give insight into that patient experience. Theoretically, if a patient is satisfied with the services, they are more likely to continue with telehealth visits. The last question is an opened ended question and allows the respondent to provide additional thoughts, benefits, and limitations of telehealth that were not covered in the questions. Overall, this question set will gather enough data to conclude whether telehealth in rural Tennessee is doing its part to close the gap in care.

\section{Sample Population}

The population for this study is facilities in the Tennova network, part of Community Health Systems (CHS). CHS is one of the nation's leading operators of general acute care hospitals. They provide quality healthcare for residents and contribute to the economic development of their communities (CHS, 2015). A total of ten facilities were surveyed, all of which are in Tennessee, as well as the CHS corporate office. I sent the surveys to the Chief Nursing Officer and requested he/she forward them to their clinical and administrative teams.

\section{Data Collection Instrument}


An electronic survey was disseminated via recruitment email (Appendix-A). The email included information on the research project and the purpose of the questionnaire. In addition to the electronic survey, paper surveys were disseminated in select facilities at nurses' stations throughout select hospitals. Nurses' stations surveyed included: Intensive Care Unit (ICU), Radiology, and Surgical Unit. While speaking to staff about telehealth, I performed non-structured interviews to expand on positive or negative remarks that were made. I asked for the interviewee to expound on their statement. Surveys were also disseminated to the Emergency Department's Nurses' station, but the staff was unable to answer the survey because of high patient intake volume. I took the data received from the paper surveys and compiled them with the electronic responses onto a single excel spreadsheet.

\section{Data Analysis}

The survey was sent to ten CFOs in facilities across the Tennova Network. Three CFOs sent the surveys to their team and one responded to my survey request but did not complete the survey due to their telehealth system not being fully implemented. The response rate for my electronic surveys was $30 \%$. The response rate for my onsite visit to Tennova Lebanon was more promising. I brought 50 paper surveys and had 30 completed, giving a response rate of $60 \%$. Five surveys were sent out on a corporate level, resulting in two responses. The total average response rate for this project is $54 \%$.

These facilities were selected as the sample population because of their location and the services they offer through telehealth. They utilize telehealth technology in 
departments such as Radiology, Intensive Care Unit, and the Emergency Department and could provide valuable information towards my research. In order to qualify for this project, facilities must be in Tennessee and have a telehealth system fully integrated into their organization. As such, I requested responses from individuals from the clinical and administrative professions who have knowledge about the facility's telehealth system. 


\section{Chapter 4: Results}

As shown in Figure-1, 46\% of all respondents are Nurses. Administrative staff accounted for $26 \%$ of the responses, and "Other" was selected for the remaining $28 \%$. The "Other" respondents included an Emergency Department Director and a Radiology Technician. No Physicians, Nurse Practitioners, or Physicians Assistants responded to the survey.

Position in the Organization

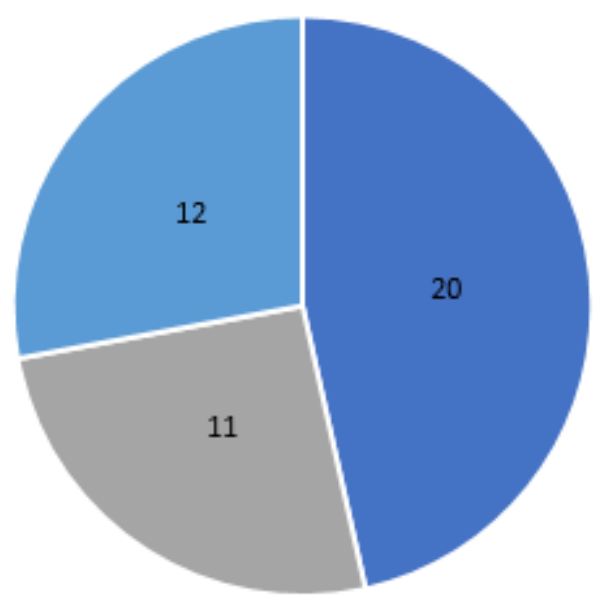

$$
\begin{aligned}
& \text { n Nurse } \\
& \text { n Physician } \\
& \text { " Administrative } \\
& \text { = PA or NP } \\
& \text { " Other }
\end{aligned}
$$

(Figure-1 Respondents' Position in Organization)

The age range with the most respondents was 26-50 years of age accounting for 27 of 43 individuals, or $63 \%$ of respondents. The age range 51-65 years account for $15(35 \%)$ of respondents. There one individual (2\%) in the age ranges of 18-25 and zero respondents of $66+$ years of age. 


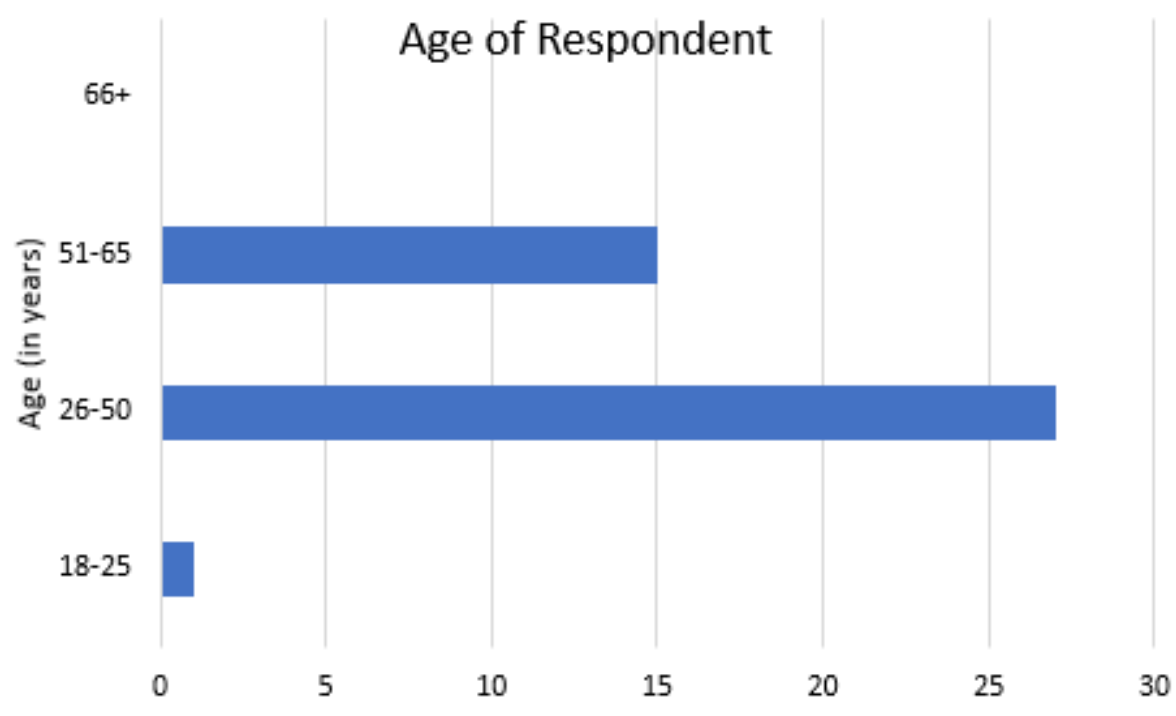

(Figure-2 Age of Respondent)

Of the ten hospitals surveyed, only five responded. I received one response via email from hospital administration stating, "We begin Telemedicine on September 26th. I am sorry we cannot be a resource for you." The hospitals that responded through the survey link were Turkey Creek Medical Center (5), Tennova Health Shelbyville (4), and LaFollette Medical Center (2). Two (2) individuals from CHS Corporate office responded to my electronic survey. I went to Tennova Lebanon with paper surveys, resulting in a more significant number of respondents (30). 


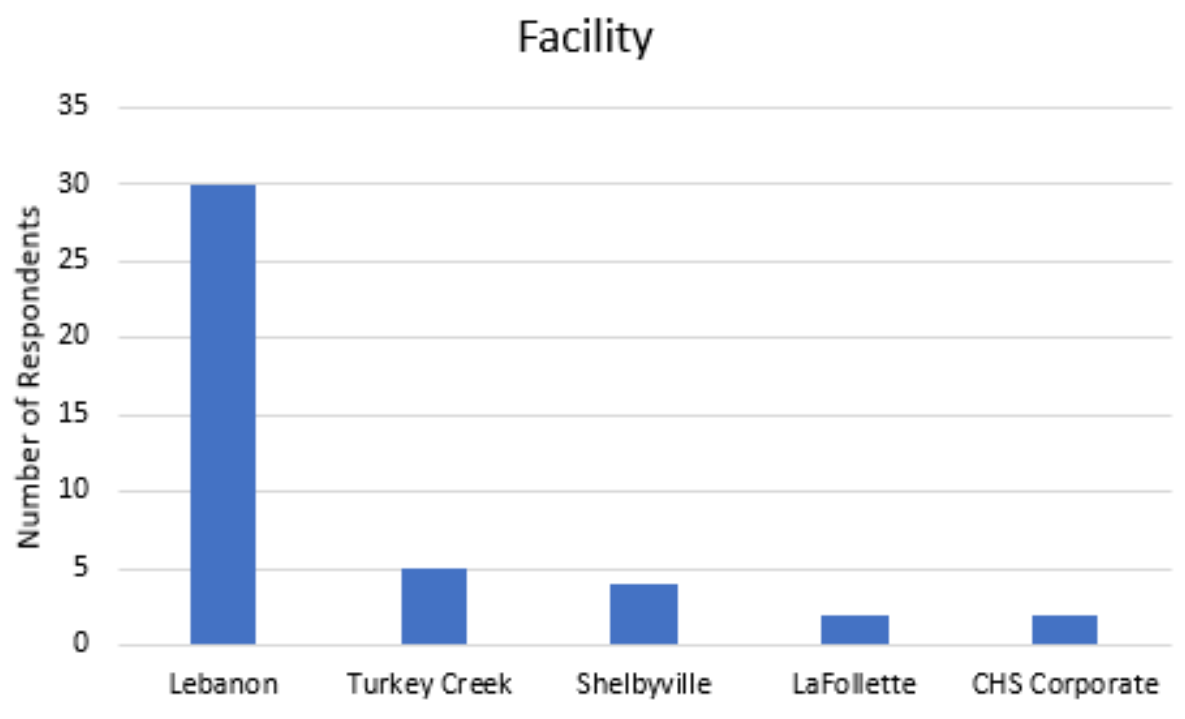

(Figure-3 Place of Employment)

A significant percentage (63\%) of participants has used telehealth for one to five years.

Six to ten years (19\%) and less than 1 year (12\%) are close in results as are $21+$ years $(5 \%)$ and $11-20$ years $(2 \%)$. 


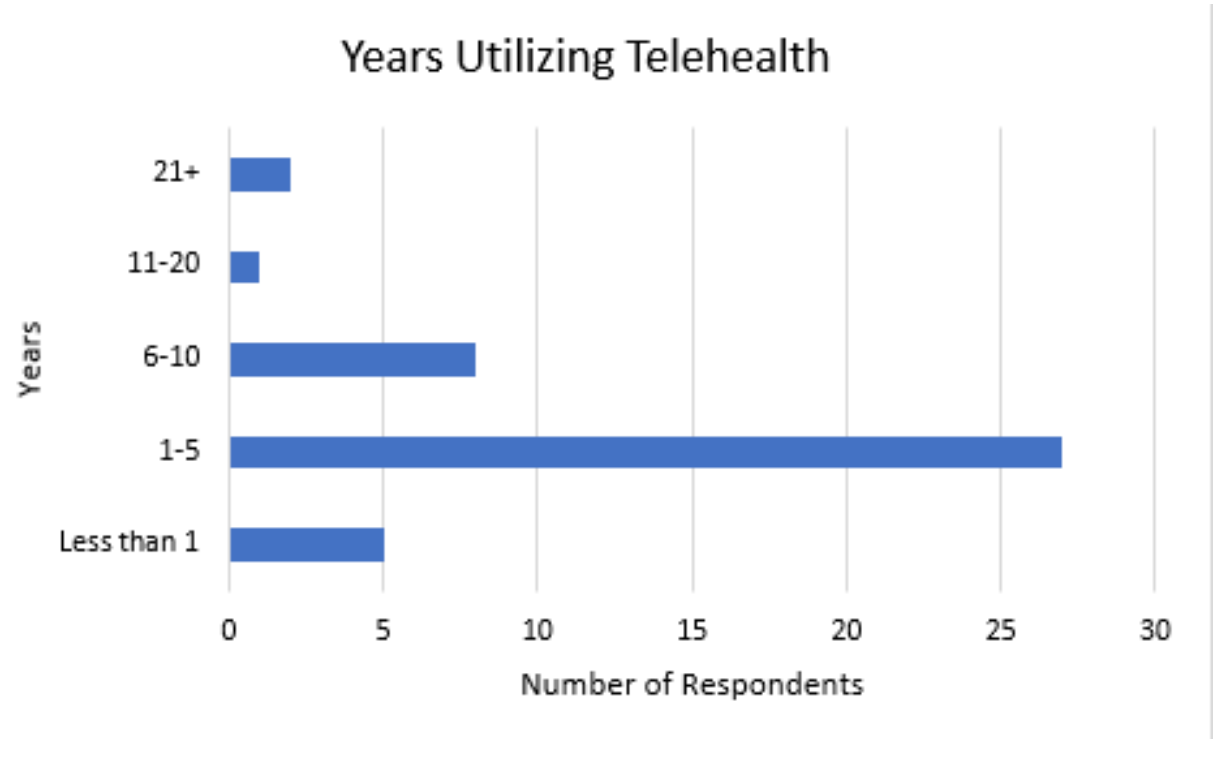

(Figure-4 Years Utilizing Telehealth)

Over half (60\%) of individuals who completed the survey answered "Yes" when asked if telehealth is cost-efficient. 13 of 43 (30\%) respondents selected "I don't know." A large portion of the sample population is part of the clinical team and may not have access to financial information. Only $9 \%$ of respondents (4) do not think telehealth is cost-efficient. 


\section{Is Telehealth Cost Efficient?}

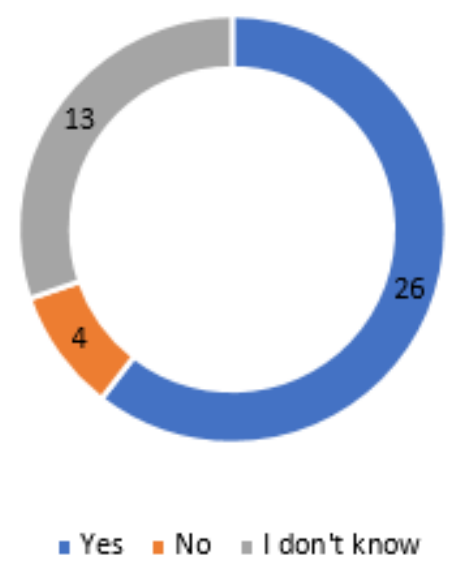

(Figure-5 Cost Efficiency of Telehealth)

As shown by the graph in Figure-6 below, most respondents (24) agree that telehealth improves overall patient care accounting for $56 \%$ of responses. Ten individuals $(23 \%)$ do not think telehealth improves care and nine (21\%) answered: "I don't know."

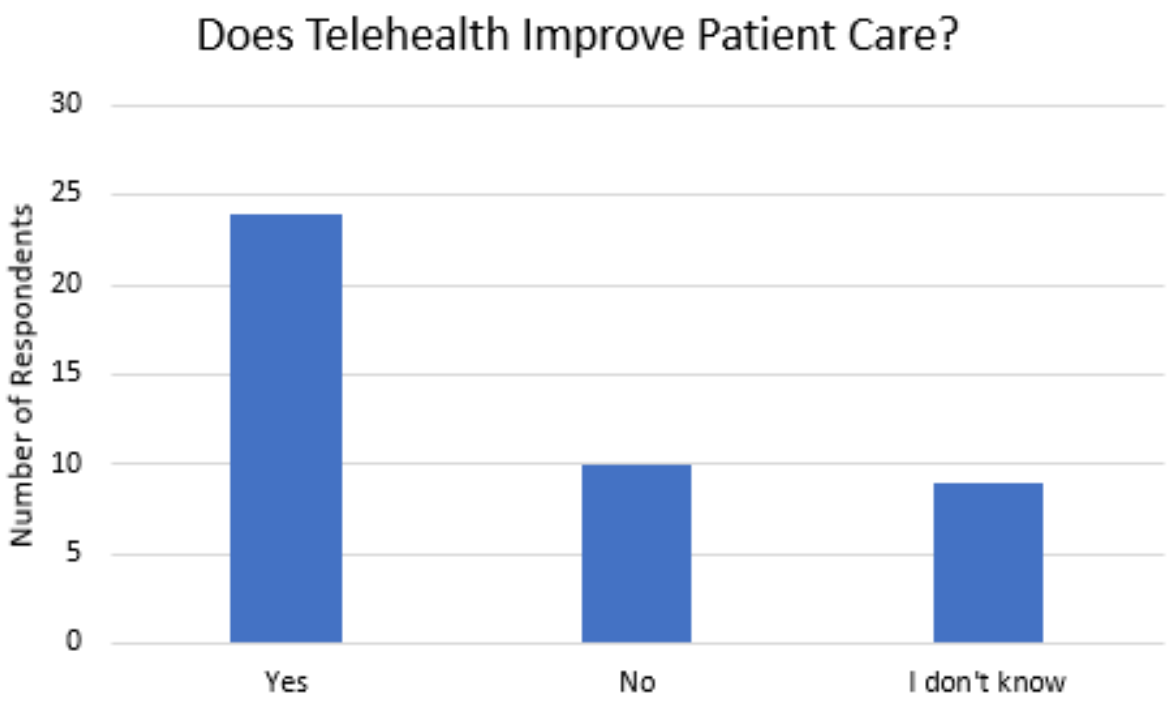

(Figure-6 Patient Care Improvement) 
When asked about connectivity issues, 19 of 43 answered "rarely," and 14 answered "sometimes." 7 respondents answered "Never," and three did not answer this question.

\section{Do you and/or the patient experience internet connectivity issues?}

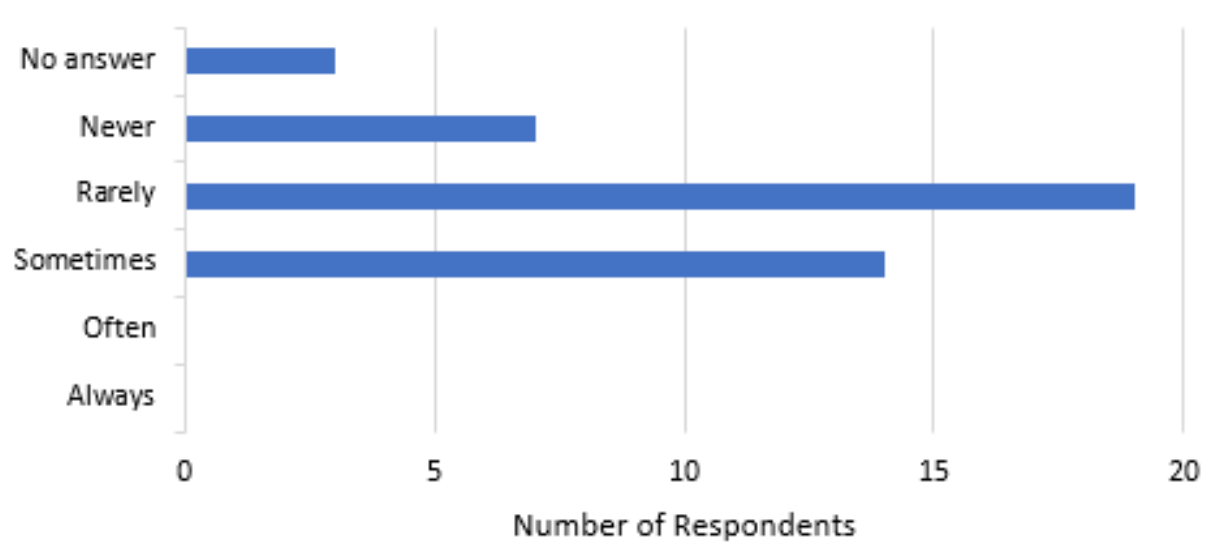

(Figure-7 Telehealth Connectivity Issues)

The histogram shown in Figure-8 shows the most significant barriers of telehealth. Respondents were asked to rank the barriers with "1" being the greatest barrier and "5" being the least. By glancing at the graph, it is easy to determine which barriers have the greatest impact. "Funding for equipment" had the most ratings as the greatest barrier and "Patient involvement/technology literacy" had the second largest number of ratings for the most significant barrier. 


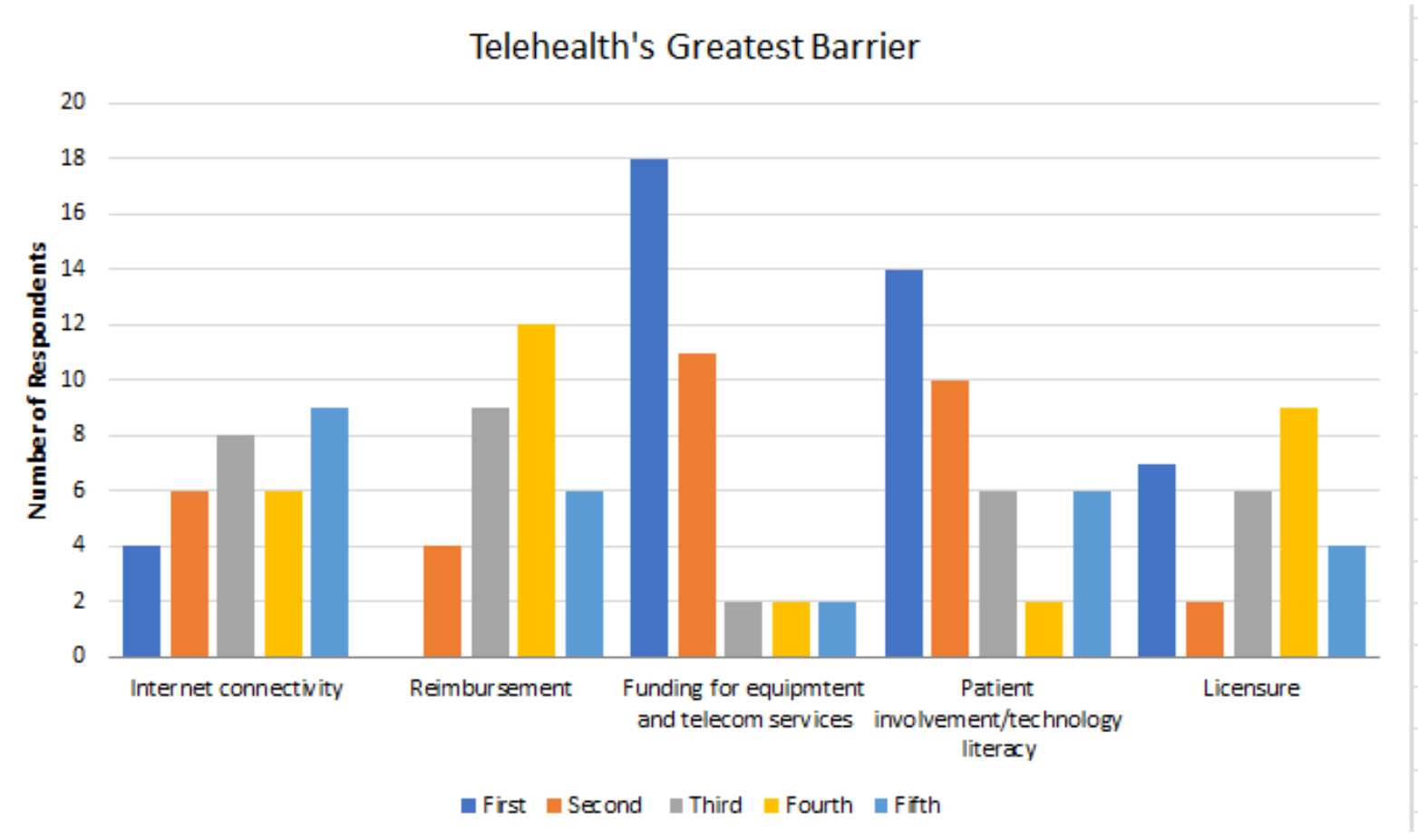

(Figure-8 Telehealth's Greatest Barriers)

Figure-9 shows a relatively low percentage of patients continuing telehealth services after the initial visit. Over half of respondents (51\%) reported the retention level is $30 \%$ or below. 16 of 43 respondents answered, "I don't know" and only four individuals reported "50\% or more". 


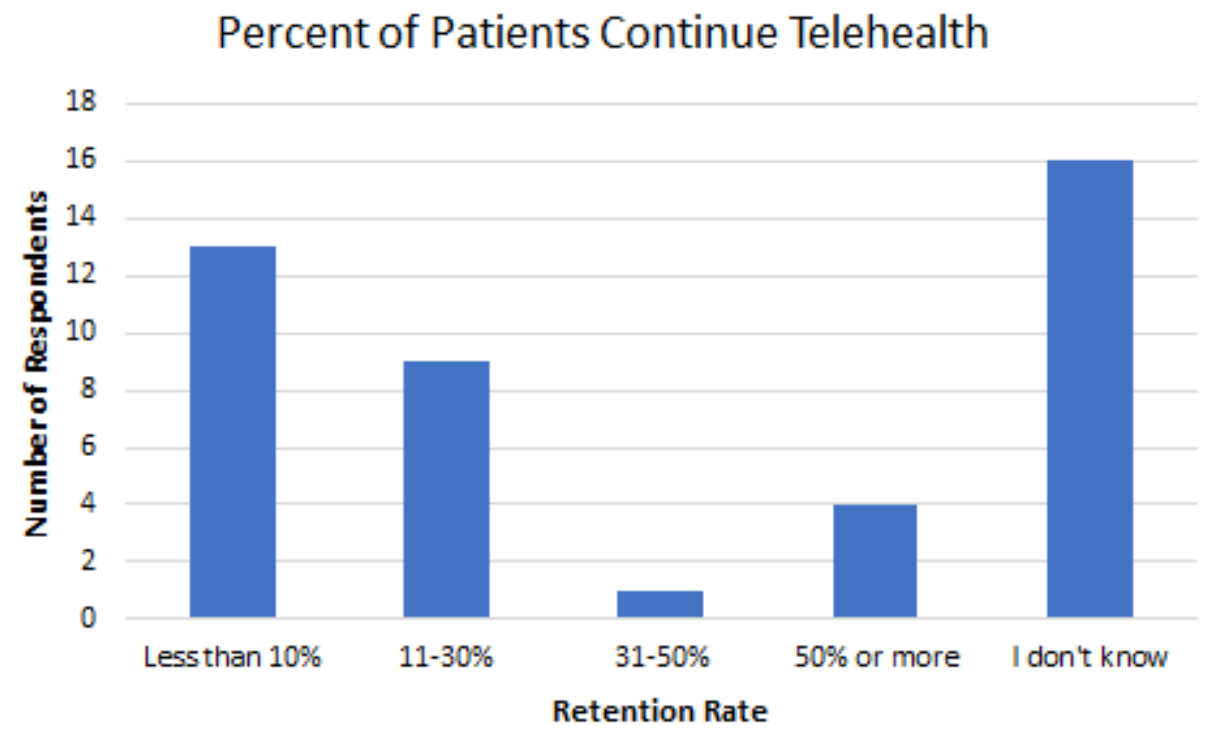

(Figure-9 Patient Retention)

Figure-10 provides quotations from survey responses.

\begin{tabular}{|c|}
\hline Respondents' comments on telehealth services \\
\hline Teach telehealth in nursing school \\
\hline $\begin{array}{c}\text { Physicians agreeing to use telemedicine for other specialties like infectious disease or general } \\
\text { neurology } \mathrm{f} / \mathrm{u} .\end{array}$ \\
\hline It has been a wonderful service. We have telemedicine for neuro, Mental health, and \\
respiratory.We are able to keep $>75 \%$ of initial consults. \\
\hline $\begin{array}{c}\text { Providers are not comfortable enough without in person consults especially in specialty areas } \\
\text { such as Neurology }\end{array}$ \\
\hline Decreased wait time for behavioral health consults \\
\hline $\begin{array}{c}\text { Telehealth has helped our facilities reach an unpresedented level of care. We are able to offer } \\
\text { services that, with out the use of remote user technology, would be a challenge. }\end{array}$ \\
\hline
\end{tabular}

(Figure-10 Responses to open ended question) 


\section{Chapter 5: Discussions}

Based on my findings, telehealth is proving to be a valuable resource in closing the gap of care in Rural Tennessee. Telehealth has increased access to patients in areas that do not have specialty physicians on site, leading to reduced wait times for consults. Also, telehealth has increased cost savings for both the hospital and patient. Below is a breakdown of answers I received for cost efficiency and improved patient care based on the variable "Position in the organization".

In Table-2 shown below, I analyzed the respondents' opinion of the cost efficiency of telehealth based on their position in the organization. I found a large portion (9 of 11) of administrators found telehealth cost effective, while only one disagreed.

About half of nurses and individuals in other positions found telehealth cost efficient.

\begin{tabular}{|l|c|c|c|c|}
\hline Cost Efficiency & Yes & No & I don't know & Total \\
\hline \multirow{2}{*}{$\begin{array}{l}\text { Administrative } \\
\text { Nurse }\end{array}$} & $82 \%$ & $9 \%$ & $9 \%$ & $100 \%$ \\
\cline { 2 - 5 } Other & $55 \%$ & $10 \%$ & $35 \%$ & $100 \%$ \\
\cline { 2 - 5 } & $50 \%$ & $8 \%$ & $42 \%$ & $100 \%$ \\
\hline
\end{tabular}

(Table-2 Cost Efficiency by Position)

\begin{tabular}{|l|l|l|l|l|}
\hline Cost Efficiency & \multicolumn{1}{|c|}{ Yes } & \multicolumn{1}{|c|}{ No } & \multicolumn{1}{c|}{ I dotal } \\
\hline $\begin{array}{l}\text { Administrative } \\
\text { Nurse }\end{array}$ & $=\operatorname{SUM}(9 / 11)$ & $=S U M(1 / 11)$ & $=S U M(1 / 11)$ \\
\cline { 2 - 5 } Other & $=S U M(11 / 20)$ & $=S U M(2 / 20)$ & $=S U M(7 / 20)$ & $=S U M(C 3: E 3)$ \\
\cline { 2 - 4 } & $=S U M(6 / 12)$ & $=S U M(1 / 12)$ & $=S U M(5 / 12)$ & $=S U M(C 5: E 5)$ \\
\hline
\end{tabular}


(Table-3 Cost Efficiency by Position Excel Formulas)

When comparing answers by position to the question, "In your experience, has telehealth helped improve overall patient care?" I notice the answers for Nurse and Other are spread out between the answer selections. Nurses had the highest rate of disagreeing that telehealth improved care (35\%), and Administrative had the highest percentage (91\%) of agreeing with care improvement.

\begin{tabular}{|l|c|c|c|c|}
\hline Improve Patient Care & Yes & No & I don't know & Total \\
\hline \multirow{2}{*}{$\begin{array}{l}\text { Nuministrative } \\
\text { Other }\end{array}$} & $91 \%$ & $0 \%$ & $9 \%$ & $100 \%$ \\
\cline { 2 - 5 } & $45 \%$ & $35 \%$ & $20 \%$ & $100 \%$ \\
\cline { 2 - 5 } & $42 \%$ & $25 \%$ & $33 \%$ & $100 \%$ \\
\hline
\end{tabular}

(Table-4 Care Improvement by Position)

\begin{tabular}{|c|c|c|c|c|}
\hline Improve Patient Care & Yes & No & I don't know & Total \\
\hline Administrative & $=\operatorname{SUM}(10 / 11)$ & $=\operatorname{SUM}(0 / 11)$ & $=\operatorname{SUM}(1 / 11)$ & =SUM(C8:E8) \\
\hline Nurse & $=\operatorname{SUM}(9 / 20)$ & $=\operatorname{SUM}(7 / 20)$ & $=\operatorname{SUM}(4 / 20)$ & =SUM(C9:E9) \\
\hline Other & $=\operatorname{SUM}(5 / 12)$ & $=\operatorname{SUM}(3 / 12)$ & $=\operatorname{SUM}(4 / 12)$ & $=S U M(C 10: E 10)$ \\
\hline
\end{tabular}

(Table-5 Care Improvement by Position Excel Formulas) 
While most responses were of positive nature, I did receive multiple recommendations from Registered Nurses based on their telehealth experience. Their main concern was the lack of telehealth education taught during nursing school. One nurse spoke of her uneasiness while assisting with a telehealth session. She gave the example of the remote physician having her assess both wrists of a patient and reporting if there was any difference. She stated the physician would be able to pick up on differences that she could not detect, based on the level of training the physician has. Another nurse said there is a long wait time for the patient and assisting nurse while they are waiting for the physician to appear on the other line. She stated there was only one available video conference machine and there is often a waiting time to use it. She suggested a better telehealth scheduling or notification system. These recommendations, if corrected, could lead to increased performance in telehealth services.

Overall, telehealth is on its way to improving access to care and overcoming barriers that are presented. The general feedback for services provided was positive, and many individuals are excited about the future of telehealth in their community. 
Chapter 6: Conclusion and Recommendations

\section{Recommendations}

I recommend there be more research on telehealth in rural Tennessee in hopes that the investigation will serve as an educational resource.

- Is there a way to bolster communication between a remote physician and a nurse present at the bedside during the telehealth sessions?

- How can the rural community receive education on telehealth?

- What aspects will increase the retention rate of patients utilizing telehealth services after the initial consult?

- Research funding options to implement a higher number of telehealth devices.

- Conduct telehealth research solely based on nurses' experience.

Nurses play a large role in patients' care and from my research, it is nurses who see the most issues with telehealth services in their facilities. I think if research focused on this technology from a nurses' perspective, we will continue to see the gap in care decrease in the rural population.

\section{Conclusion}

Telehealth has come a long way since the use of radios in the 1920's. This service has been a game changer in the healthcare industry as patients now have better access to care. It is unfortunate that many rural hospitals, ones that communities rely on, are 
closing because of financial burden; however, with the use of telehealth, patients will be able to receive the care they need without traveling far distances.

There are still barriers that exist, such as the "seven deadly barriers," but the positive outcomes seen using telehealth are exceptional. Telehealth has helped close the gap in care seen in rural Tennessee, and I cannot wait to witness what the future of telehealth holds. 


\section{Appendix A: Recruitment Letter}

Hello,

My name is Kara Bianchini, and I am a student enrolled in the Master of Health Informatics and Information Management program at the University of Tennessee Health Science Center. I am in my final semester and working on my applied research project titled "Telehealth in Rural Tennessee- closing the gap in care?". It has come to my attention that rural hospitals are closing at a rapid rate in Tennessee leaving a gap in care for the residents. I would like to conduct research at facilities that offer telehealth to these rural areas and learn if telehealth is being utilized, its effectiveness and barriers. As part of my project, I am disseminating a brief questionnaire to Tennessee healthcare facilities that utilize telehealth. In an effort to gather efficient data, I humbly ask for you to complete the brief, ten questions through the link provided below, or attached to this form if in-person. My project has been reviewed and approved by the University of Tennessee Health Science Center IRB. Please feel free to contact my research advisor, Dr. Sajeesh Kumar at (901) 448-2125, if you have any questions regarding the research project. Your assistance is greatly appreciated.

Link: (survey URL here)

Attachments: Questionnaire Consent Form

Very Respectfully,

Kara Bianchini

Kbianchi@uthsc.edu 


\section{Appendix-B Questionnaire}

\section{Telehealth in Rural Tennessee Questionnaire}

1. What is your position in the organization?

a. Physician

b. Nurse

c. Administrative

d. Physician Assistant

e. Nurse Practitioner

f. Other

2. What is your age range?

a. $18-25$

b. $26-50$

c. $51-65$

d. $66+$

3. What facility are you associated with?

4. How many years have you utilized telehealth?

a. Less than 1

b. 1-5

c. $6-10$

d. $11-20$

e. $20+$

5. In your experience, has telehealth helped improve overall patient care?

a. Yes

b. No

c. Don't know

6. Do you experience connectivity issues during sessions?

a. Always

b. Often

c. Sometimes

d. Rarely

e. Never

7. In your opinion, what is the largest barrier for telehealth in rural Tennessee? (Please rate 1-5; $1=$ greatest, $5=$ =least)

_ Internet connectivity

- Reimbursement

_ Funding for equipment and telecom services

_ Patient involvement/technology literacy

_ Licensure 
8. Is telehealth cost efficient?

a. Yes

b. No

c. I don't know

9. What percentage of your patient population continues with telehealth visits after the initial visit?

a. Less than $10 \%$

b. $11 \%-20 \%$

c. $21 \%-30 \%$

d. $31 \%-40 \%$

e. $41 \%-50 \%$

f. $50 \%$ or more

g. Don't know

10. Please provide any additional thoughts on telehealth in your organizationbenefits, limitations, recommendations 


\section{References:}

Community Health Systems. (2015). Home page. Retrieved from: www.chs.net

Foley \& Lardner, LLP. (2017). Telemedicine and digit health survey. Retrieved from: https://www.foley.com/files/uploads/2017-Telemedicine-Survey-Report-11-817.pdf

Jackson, Brittney. (2018). Life after death of a hospital. Jackson Son-USA Today Network. Retrieved from: https://www.jacksonsun.com/story/news/local/2018/01/19/life-after-deathhospital/1007168001/

Leagle. (2017). Tennessee v. Federal Communications Com’n. 832 F.3d 597 (2016). Retrieved from: https://www.leagle.com/decision/infco20160810085

National Academies Press. (2012). The role of teleheah in an evolving heath care environment: workshop summary. Retrieved from: http://www.nap.edu/read/13466/chapter/4\#15

The Office of the National Coordinator for Health Information Technology (ONC). (n.d).

Health IT: advancing America's health care. Retrieved from: https://www.healthit.gov/sites/default/files/pdf/health-information-technologyfact-sheet.pdf 
Schadelbauer, Rick. (2017). Anticipating economic returns of rural teleheal. The Rural Broadband Association. Retrieved from: https://www.ntca.org/sites/default/files/documents/201712/SRC_whitepaper_anticipatingeconomicreturns.pdf

TN Department of Health. (n.d.). Rural areas. Retrieved from: https://www.tn.gov/health/cedep/environmental/healthy-places/healthyplaces/land-use/lu/rural-areas.html

Wicklund, Eric. (2018). CMS proposes more Medicare reimbursement for telehealth. MHealth Intelligence. Retrieved from: http://mhealthintelligence.com/news/cmsproposes-more-medicare-reimbursement-for-telehealth-rpm 